\title{
Bond Strength of Gold Alloys Laser Welded to Cobalt-Chromium Alloy
}

\author{
Ikuya Watanabe $e^{1, *}$ and Cameron Wallace ${ }^{2}$ \\ ${ }^{1}$ Department of Biomaterials Science, ${ }^{2}$ Department of General Dentistry, Baylor College of Dentistry, Texas A\&M \\ Health Science Center, Dallas, TX, 75246 USA
}

\begin{abstract}
The objective of this study was to investigate the joint properties between cast gold alloys and Co-Cr alloy laser-welded by Nd:YAG laser. Cast plates were fabricated from three types of gold alloys (Type IV, Type II and low-gold) and a Co-Cr alloy. Each gold alloy was laser-welded to Co-Cr using a dental laser-welding machine. Homogeneouslywelded and non-welded control specimens were also prepared. Tensile testing was conducted and data were statistically analyzed using ANOVA. The homogeneously-welded groups showed inferior fracture load compared to corresponding control groups, except for Co-Cr. In the specimens welded heterogeneously to Co-Cr, Type IV was the greatest, followed by low-gold and Type II. There was no statistical difference $(\mathrm{P}<0.05)$ in fracture load between Type II control and that welded to Co-Cr. Higher elongations were obtained for Type II in all conditions, whereas the lowest elongation occurred for low-gold welded to Co-Cr. This study indicated that, of the three gold alloys tested, the Type IV gold alloy was the most suitable alloy for laser-welding to Co-Cr.
\end{abstract}

Key Words: gold alloys, cobalt chromium alloy, laser welding, bond strength.

\section{INTRODUCTION}

Cobalt-chromium alloys are commonly used to fabricate metal frameworks for removable partial dentures because of their strong mechanical properties, high corrosion resistance and low cost [1]. When dental prosthetic frameworks are fabricated, they are often soldered or welded due to constraints of the complicated design and accuracy $[2,3]$. The functional life of the soldered or welded prostheses is dependent on the joint strength of the metal frameworks. A weak joint reduces the longevity of a complicated prosthesis. The soldering and welding are usually conducted by means of conventional gas-torch [4-7], electrode [8], infrared beam $[5,7]$, or tungsten inert gas (TIG) [9-11]. One of the joining methods is laser welding. The use of laser welding in dentistry has increased during the past decade [9, 11-20]. Since laser energy can be concentrated on a small area, there are fewer effects of heating and oxidation on the area surrounding the spot to be welded. Therefore, the broken metal frameworks of partial dentures can be fixed without burning any combustible polymer materials such as denture base resins and resin composites. It should be noted that conventional soldering can't be applied to fix broken metal frameworks because the heat generated during soldering directly damages the polymer material.

It is sometimes necessary in clinical practice to connect denture metal frameworks to different types of alloy frameworks to obtain rigid stability; for example, the newlyfabricated anterior Konus gold crowns or bridges connected to existing posterior removable partial dentures with cobalt-

*Address correspondence to this author at the Department of Biomaterials Science, Texas A\&M Health Science Center, Baylor College of Dentistry, 3302 Gaston Ave., Dallas, TX 75246, USA; Tel: +1-214-370-7006; Fax: +1-214-370-7001; E-mail: iwatanabe@bcd.tamhsc.edu chromium frameworks [10]. Although it is important to know how well the different types of alloys can be welded by laser, there is little information available about the weld strength between cobalt-chromium and gold alloys including the high- or low-content gold alloys. In the present study, three types of gold alloys were investigated in terms of welding strength to a cobalt-chromium alloy using a dental Nd:YAG laser-welding machine.

\section{MATERIALS AND METHODS}

Three gold alloys employed in this study were: (1) ADA Type II gold alloy (Ney-Oro A1; Au: 77.5\%, Ag: $12.5 \%, \mathrm{Cu}$ : 7.3\%, Pd: 2.0\%, Zn: <1\%; Degussa-Ney Inc., Bloomfield, CT), (2) ADA Type IV gold alloy (Ney-Oro 60; Au: 56\%, Ag: $19.9 \%, \mathrm{Cu}: 17 \%$, Pd: 4\%, Zn: 3\%; Degussa-Ney Inc., Bloomfield, CT), and (3) low-gold/high-silver content alloy (New Gold Para; Au: 12\%, Ag: 51\%, Pd: 20\%, Cu: 14.5\%; Ishifuku Corp., Tokyo, Japan) (henceforth referred to as "low-gold"). Also tested was a cobalt-chromium alloy (Vitallium; Co: 60.6\%, Cr: 31.5\%, Mo: 6.0\%; Austenal, Inc., Chicago, IL).

Plate wax patterns were prepared for the non-welded control specimens $(0.5 \times 3.0 \times 20.0 \mathrm{~mm})$ and the welded specimens $(0.5 \times 3.0 \times 10.0 \mathrm{~mm})$. The wax plates for the gold alloys were invested in the molds with a cristobalite investment (Crisobalite, Whip-Mix Corp., Louisville, KY) and each alloy was cast into the mold using a broken-arm centrifugal casting machine (Kerr Centrifico, Kerr Manufacturing Corp., Romulus, MI). Wax patterns for the Co-Cr alloy were invested with phosphate-bonded investment (Green Stripe, Nobilium) and the alloy was cast into the mold using an induction-melting centrifugal casting machine (Modular 4, CMP Industries Inc., Albany, NY). The overall burnout schedule prior to casting followed the manufacturer's in- 
structions. The mold temperatures for the gold alloys and the Co-Cr alloy at the time of casting were $700^{\circ} \mathrm{C}$ and $980^{\circ} \mathrm{C}$, respectively. After casting, the molds were allowed to benchcool to room temperature. The castings were then divested and cleaned by air-abrasion with $50 \mu \mathrm{m} \mathrm{Al}_{2} \mathrm{O}_{3}$ particles and were ultrasonically cleaned in ethanol for 10 minutes.

After the $3.0 \times 0.5 \mathrm{~mm}$ surfaces of two plates $(0.5 \times 3.0 \times$ $10 \mathrm{~mm}$ ) were polished with No. $600 \mathrm{SiC}$ paper, they were butted against one another using a jig. $\mathrm{Co}-\mathrm{Cr}$ alloy plates were adjoined to plates from each of the three gold alloys. Homogeneously-welded specimens were also prepared for each alloy. The assembled cast plates were then welded with a Nd:YAG laser (NeoLaser L, Girrbach Dental Systems, Pforzheim, Germany) with a pulse duration of $10 \mathrm{~ms}$, a spot diameter of $1 \mathrm{~mm}$ and a pulse frequency of $1 \mathrm{~Hz}$. The homogeneously-welded group used a constant voltage of $260 \mathrm{~V}$, which was determined as the optimal voltage for this group in previous studies $[21,22]$ of the penetration depth of the laser into each alloy. However, the laser at this voltage was destructive to the heterogeneously-welded group, so the voltage for this group was reduced to $200 \mathrm{~V}$. The laser was perpendicularly applied to the interface of each pair of plates. Each specimen was bilaterally welded with five laser spots per side (Fig. 1). Three laser spots were linearly applied to plied to cover the $3 \mathrm{~mm}$ width on both sides. Two more laser spots, which overlapped with $50 \%$ of the three previously applied spots, were then applied to both sides. The laser welding was performed under the argon gas shielding, in which a flow of argon gas was directed near the surface of the abutted area from two nozzles set at an angle of $45^{\circ}$ on both sides above the specimen. The distance between the spot to be welded and each nozzle was approximately $1 \mathrm{~cm}$.

Tensile testing was conducted using a universal testing machine (Model 5567, Instron Corp., Canton, MA) at a crosshead speed of $0.25 \mathrm{~mm} / \mathrm{min}$ and a gauge length of 10 $\mathrm{mm}$. Grips were attached $5 \mathrm{~mm}$ from each end. The maximum failure load $(\mathrm{N})$ and elongation $(\%)$ at the failure were recorded; and the means and standard deviations $(n=6)$ were calculated. The data were statistically analyzed using ANOVA/Tukey's HSD test and a Student-T test at a significance level of $\alpha=0.05$. After tensile testing, the fractured surfaces were examined with a scanning electron microscope (SEM)(JSM-6300, JEOL, Peabody, MA) to determine possible mechanisms of fracture.

\section{RESULTS}

For all alloys, the non-welded control specimens withstood greater failure loads (Fig. 2) than the homogeneously-

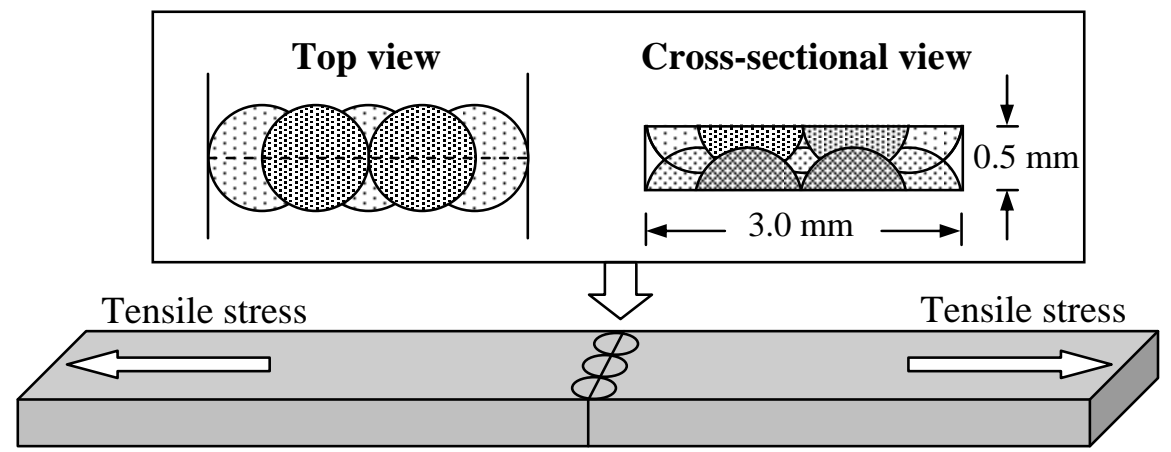

Fig. (1). Laser-welding configuration of test specimens.

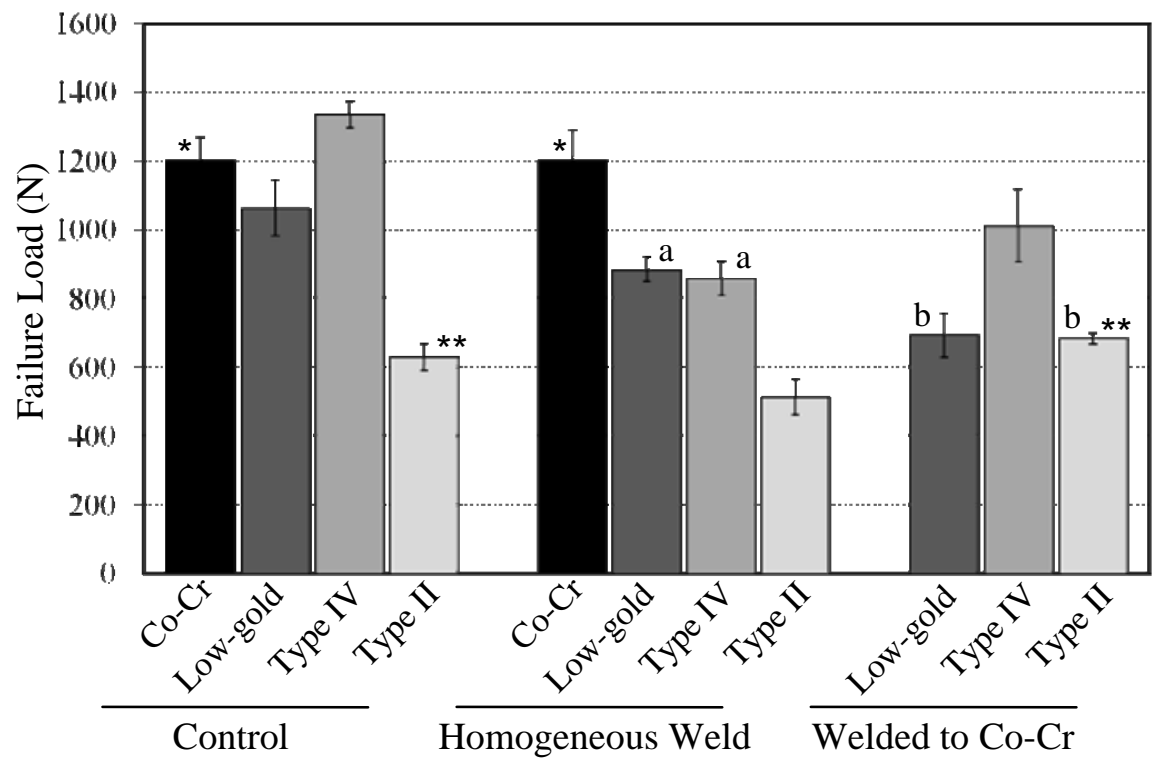

Fig. (2). Mean failure loads $(\mathrm{N})$. Asterisks $\left({ }^{*},{ }^{* *}\right)$ indicate statistically insignificant variance between different treatments of a single type of alloy, while letters $(\mathrm{a}, \mathrm{b})$ indicate insignificant difference between two alloys within the same treatment group. All significances were found at $\mathrm{p}<0.01$. 
welded group except for the Co-Cr alloy which showed no significant difference under these conditions. The decrease of the failure load from the control group to the homogeneously-welded group was highest for the Type IV gold alloy. However, the Type IV gold showed the highest values among the gold alloy groups welded to $\mathrm{Co}-\mathrm{Cr}$. There was no significant difference $(\mathrm{p}<0.05)$ between the low-gold and the Type II alloys. The Type IV and Type II alloys welded to the Co-Cr alloy exhibited higher fracture loads compared to corresponding homogeneously-welded groups. Elongation results are presented in Fig. (3). The lowest elongation values were obtained for $\mathrm{Co}-\mathrm{Cr}$ in all conditions (control, homogeneous welding and heterogeneous welding). On the other hand, the Type II gold alloy exhibited the highest elongation values for all conditions.

SEM images of magnified fracture surfaces of representative groups are presented in Fig. (4). Non-welded, $\mathrm{Co}-\mathrm{Cr}$ control specimens (Fig. 4A) exhibited a brittle dendritic fracture. Non-welded, Type IV control specimens (Fig. 4B) had a mixture of dimple fractures and brittle cleavage fractures, but the latter was more prevalent. In contrast, non-welded, Type II control specimens (Fig. 4C) had mostly dimple fracture structures. Homogeneously-welded $\mathrm{Co}-\mathrm{Cr}$ specimens (Fig. 4D) underwent brittle fine cleavages in a river pattern. Homogeneously-welded Type IV specimens (Fig. 4E) exhibited more small dimple fractures than Type IV controls. Type IV welded to $\mathrm{Co}-\mathrm{Cr}$ (Fig. 4F) fractured on the $\mathrm{Co}-\mathrm{Cr}$ side of the weld which was similar to Fig. (4D) (the majority of the break occurred at the border of the nugget on the CoCr side). Type II welded to Co-Cr (Fig. 4G) exhibited many dimple fractures similar to those of the Type II control. These specimens broke on the Type II side of the weld. None of the low-gold/Co-Cr specimens welded completely (Fig. 4H); nor did many of the Type IV welded to Co-Cr specimens. Conversely, most of the Type II group welded to Co$\mathrm{Cr}$ specimens welded thoroughly. In the homogeneously- welded group, all specimens welded completely. All lowgold, Type II, and Type IV alloys also exhibited porosities at the joint.

\section{DISCUSSION}

The fact that the homogeneously-welded gold-containing alloys withstood lower loads than the non-welded controls could be due in part to porosities introduced into the joint during the welding process. In addition, the quick melting and solidification of the welded area disrupts the $\mathrm{Au}-\mathrm{Cu}$ lattice which is preserved in the control specimens. Note that the phase transformation of the $\mathrm{Au}-\mathrm{Cu}$ system (ordering of the Au-Cu lattice) in the gold alloys, especially ADA Type III and IV gold alloys, produce the mechanical properties changes by passing through the phase transformation temperature. It is possible that the quick heating and cooling induced by welding had a localized softening effect on the alloy, similar to a solution heat treatment (quenching at the stage of $\mathrm{Au}-\mathrm{Cu}$ solid solution). It was interesting that the homogeneously-welded Co-Cr exhibited the same mean tensile stress value as the control specimens. Indeed, there was less porosity in the $\mathrm{Co}-\mathrm{Cr}$ fracture surfaces than those found in gold alloys. Another reason could be there were a few heat effects during the melting/solidification process which might occur for the gold alloys. However, the quick solidification caused the refining of grain for Co-Cr alloys when compared to the $\mathrm{Co}-\mathrm{Cr}$ control (Fig. 4A) and homogeneously-welded $\mathrm{Co}-\mathrm{Cr}$ (Fig. 4D).

In the heterogeneously-welded group, the Type IV group exhibited the highest failure load, and the failure load was greater than that of the corresponding homogeneouslywelded group (Type IV vs. Type IV). Since the majority of the breaks occurred on the Co-Cr side of the weld as seen in Fig. (4F), these results indicated that the Type IV group produced great affinity with the Co-Cr alloy for laser welding even though many of this group had incomplete welding at

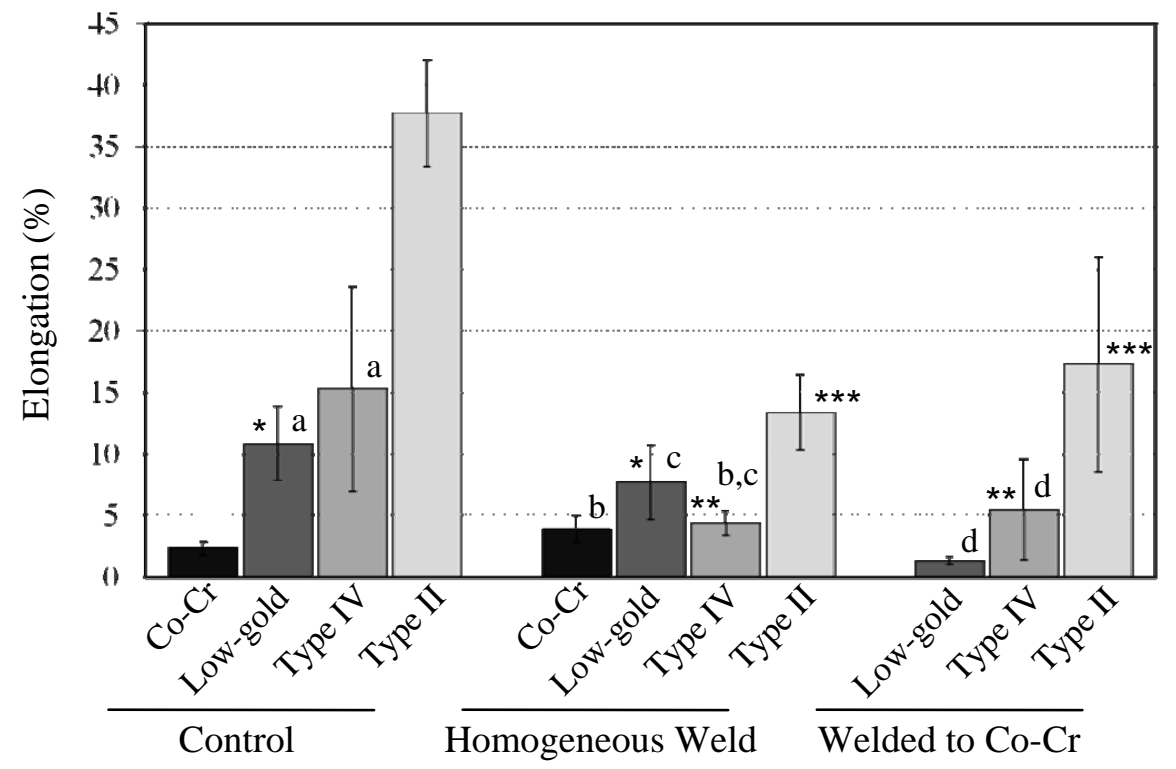

Fig. (3). Mean elongation values (\%). Asterisks $\left({ }^{*},{ }^{* *},{ }^{* * *}\right)$ indicate statistically insignificant variance between different treatments of a single type of alloy, while letters $(\mathrm{a}, \mathrm{b}, \mathrm{c}, \mathrm{d})$ indicate insignificant differences between two alloys within the same treatment group. All significances were found at $\mathrm{p}<0.01$. 

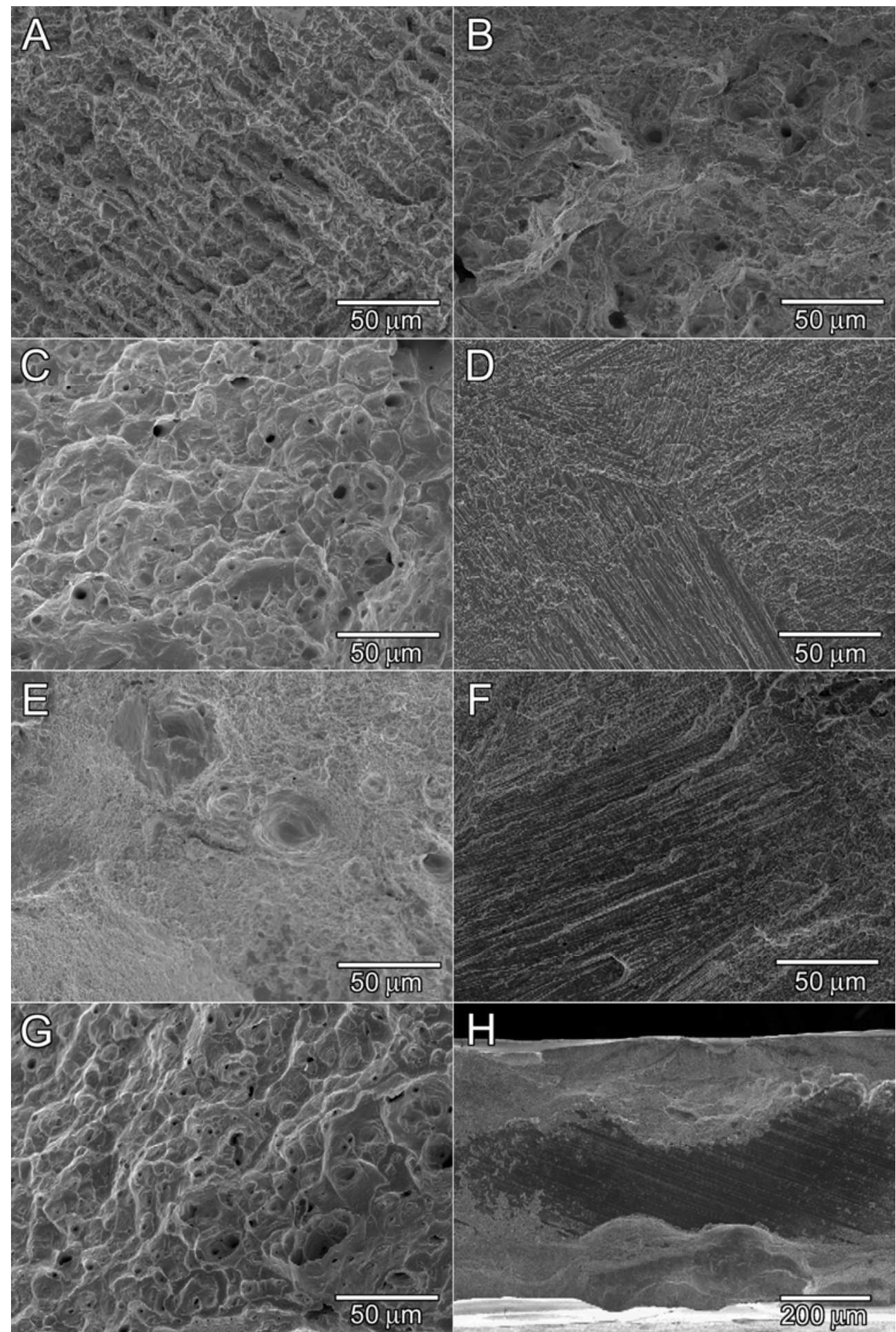

\section{$\mathrm{H}$}

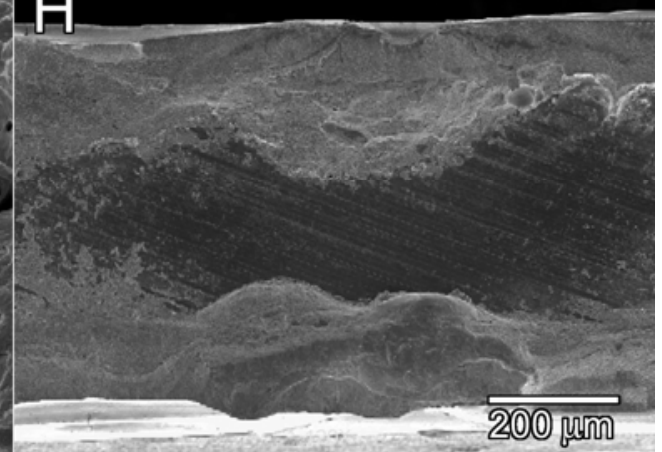

Fig. (4). Scanning electron micrographs of fracture sites. A: Co-Cr control, B: Type IV control, C: Type II control, D: Homogeneouslywelded Co-Cr/Co-Cr, E: Homogeneously-welded Type IV/Type IV, F: Heterogeneously-welded Type IV/Co-Cr, G: Heterogeneouslywelded Type II/ Co-Cr, H: Heterogeneously-welded low-gold/ Co-Cr.

the central area of the fracture surfaces. On the contrary, most of the Type II group welded to $\mathrm{Co}-\mathrm{Cr}$ fractured on the Type II side of the weld. It is interesting that this group demonstrated a higher failure load than not only that of the homogeneously-welded group (Type II/Type II), but also that of the control Type II group. Since all specimens welded completely and broke on the Type II side of the weld, the Type II group also had great affinity for $\mathrm{Co}-\mathrm{Cr}$ by laser welding. The elongation results showed the highest elongation value for the Type II group in any condition. These results correspond with the ductile dimple fracture surfaces of Type II (Figs. 4C and 4G). 
All the low-gold specimens welded to $\mathrm{Co}-\mathrm{Cr}$ remained un-welded in the central area of the fracture surface (Fig. $\mathbf{4 H}$ ), and this group could not reach the value of homogeneously-welded low-gold. Incomplete welding might occcur due to a large amount of silver ( $\mathrm{Ag})$ in the alloy. It is known that lower thermal conductivity and greater laser beam absorption results in deeper laser penetration [23]. The thermal conductivity of $\mathrm{Ag}\left(397 \mathrm{~W} \cdot \mathrm{m}^{-1} \cdot \mathrm{deg}^{-1}\right)$ is much higher than that $\left(297 \mathrm{~W} \cdot \mathrm{m}^{-1} \cdot \mathrm{deg}^{-1}\right)$ of gold $(\mathrm{Au})$. Note that the thermal conductivity of Co and $\mathrm{Cr}$ are $71 \mathrm{~W} \cdot \mathrm{m}^{-1} \cdot \mathrm{deg}^{-1}$ and $67 \mathrm{~W} \cdot \mathrm{m}^{-}$ ${ }^{1} \cdot \mathrm{deg}^{-1}$, respectively. Silver and gold have similar values (0.03) of laser beam absortion which are much lower than those of $\mathrm{Co}(0.32)$ and $\mathrm{Cr}(0.40)$. The low-gold/Co-Cr group might be able to improve the failure load by increasing the laser energy (ex. increase of voltage) to weld throughly. However, increasing the laser energy could also increase the number of porosities during welding, because the turbulence of the molten alloy incorporates ambient gas into the weld joint due to high laser energy. Further investigation will be necessary on this matter for the laser welding of heterogeneously connected low-gold/Co-Cr .

Of clinical significance is the addition of a laser welded clasp assembly that would minimize disruption of the existing cast fixed partial denture by preserving the base and artificial tooth arrangement. A round or half-round clasp could be added as a repair of removable partial dentures and would be less rigid and perhaps less likely to fracture and require another repair.

\section{CONCLUSION}

Under the limitations of this study, the following conclusions could be drawn: 1. Homogeneously laser-welded gold alloys could not achieve the strength of the original cast alloy due in part to porosities introduced into the joint using the current conditions. 2. Heterogeneously-welded Type $\mathrm{II} / \mathrm{CoCr}$ showed greater failure load than the homogeneously-welded Type II and demonstrated a joint strength comparable to the Type II control. 3. The Type IV gold showed the greatest failure load among the heterogeneously-welded to Co-Cr groups, and therefore, is the most suitable alloy to be used for laser welding to $\mathrm{Co}-\mathrm{Cr}$.

\section{ACKNOWLEDGEMENT}

This study was supported in part by Baylor Oral Health Foundation.

\section{REFERENCES}

[1] O'Brien. Dental materials and their selection. In: Base metal casting alloys. 3rd ed. Chicago IL: Quintessence Publishing; 2002, pp. 225-38.
[2] Hassan L, Juszczyk AS, Clark RK. Immediate replacement of removable partial dentures with cobalt-chromium frameworks: rationale, technology and a case report. J Oral Rehabil 2005; 32: 7725.

[3] Koke U, Wolf A, Lenz P, Gilde H. In vitro investigation of marginal accuracy of implant-supported screw-retained partial dentures. J Oral Rehabil 2004; 31: 477-82.

[4] Chaves M, Vermilyea SG, Papazoglou E, Brantley WA. Effects of three soldering techniques on the strength of high-palladium alloy solder joints. J Prosthet Dent 1998; 79: 677-84.

[5] Dominici JT, Sobczak KP, Mitchell RJ. A comparison of infraredand torch-soldering of Au-Pd and $\mathrm{Co}-\mathrm{Cr}$ metal-ceramic alloys using a high-fusing solder. J Prosthodont 1995; 4: 101-10.

[6] Lima Verde MA, Stein RS. Evaluation of soldered connectors of two base metal ceramic alloys. J Prosthet Dent 1994; 71: 339-44.

[7] Cheng AC, Chai JY, Gilbert J, Jameson LM. Investigation of stiffness and microstructure of joints soldered with gas-oxygen torch and infrared methods. J Prosthet Dent 1994; 72: 8-15.

[8] Donovan MT, Lin JJ, Brantley WA, Conover JP. Weldability of beta titanium arch wires. Am J Ortho 1984; 85: 207-16.

[9] Rocha R, Pinheiro AL, Villaverde AB. Flexural strength of pure Ti, $\mathrm{Ni}-\mathrm{Cr}$ and $\mathrm{Co}-\mathrm{Cr}$ alloys submitted to Nd:YAG laser or TIG welding. Brazil Dent J 2006; 17: 20-3.

[10] Mosch J, Hoffmann A, Hopp M. Lightning in a bottle. Dent Dialog 2004; 4: 37-51.

[11] Lindemann W. Comparison of the material quality of welded dental alloys; plasma vs. laser. Dent Dialog 2004; 4: 28-33.

[12] Iijima M, Brantley WA, Yuasa T, Muguruma T, Kawashima I, Mizoguchi I. Joining characteristics of orthodontic wires with laser welding. J Biomed Mater Res 2008; 84B: 147-53.

[13] Watanabe I, Chang J, Chiu Y. Dimensional change of laser-welded gold alloy induced by heat treatment. J Prosthodont 2007; 16: 3659.

[14] Kuo SL, El-Gendy T, Chou J, Miller RB. Fabrication of a laserwelded fixed-detachable prosthesis for immediate loading. J Prosthodont 2006; 15: 264-9.

[15] Srimaneepong V, Yoneyama T, Kobayashi E, Doi H, Hanawa T. Mechanical strength and microstructure of laser-welded Ti-6Al$7 \mathrm{Nb}$ alloy castings. Dent Mater J 2005; 24: 541-9.

[16] Suzuki Y, Ohkubo C, Abe M, Hosoi T. Titanium removable partial denture clasp repair using laser welding: a clinical report. J Prosthet Dent 2004; 91: 418-20.

[17] Ishikawa M, Kashiwabara $\mathrm{T}$, Ishida $\mathrm{O}$, Ichikawa $\mathrm{T}$. Installing magnetic keepers using laser welding. J Prosthodont 2002; 11: 4952.

[18] Liu J, Watanabe I, Yoshida K, Atsuta M. Joint strength of laserwelded titanium. Dent Mater 2002; 18: 143-8.

[19] Chai T, Chou C. Mechancial properties of laser-welded cast titanium points under different conditions. J Prosthet Dent 1998; 79: 477-83.

[20] Berg E, Wagner W, Davik G, Doots ER. Mechanical properties of laser-welded cast and wrought titanium. J Prosthet Dent 1995; 74 : 250-7.

[21] Watanabe I, Baba N. Effect of welding parameters on penetration of Nd: YAG laser into cast $\mathrm{Ti}$ and $\mathrm{Au}-$ and Ag-based alloys. Quint Int 2007; 38: 41-6.

[22] Baba N, Watanabe I. Penetration depth into dental casting alloys by Nd:YAG laser. J Biomed Mater Res 2005; 72B: 64-68.

[23] Togaya T, Shinosaki T. Introduction to laser welding in dentistry (1). Quint Dent Tech 1999; 24: 740-49. 